\title{
O PROGRAMA TOPA NO CONTEXTO DO MUNICÍPIO DE CANDEIAS
}

\author{
Ana Lucia de Freitas Caribé 1 \\ Rosemeire de Oliveira Saturno ${ }^{2}$
}

\begin{abstract}
Resumo
A alfabetização é uma porta de acesso para o processo de autodeterminação, de empoderamento, inserção e reinserção social. Acredita-se que a alfabetização possibilita o acesso a melhores condições de trabalho e renda, bem como promove mudanças importantes na relação dos jovens, adultos e idosos como o mundo. Em face desta realidade, o presente artigo tem como objetivo analisar o Programa Todos pela Alfabetização - TOPA como fator de ascensão social no Município de Candeias - Bahia. Para o desenvolvimento deste estudo foi adotado o método descritivo exploratório, com abordagem qualitativa e um questionário para coleta de dados sobre o tema em questão $O$ referido trabalho foi desenvolvido com base em pesquisa bibliográfica com a finalidade de construir um embasamento teórico a partir de conhecimentos já catalogados como: livros, artigos científicos, revistas, relatórios, publicações periódicas, internet entre outras fontes. Assim, neste artigo analisou-se o Programa Todos pela Alfabetização - TOPA como fator de ascensão social no município de Candeias. Frente aos dados obtidos, concluiu-se que o programa tem contribuído precariamente para a ascensão social daqueles que dele participa, pois, diante das suas fragilidades, a continuidade dos estudos não é garantida, negando, portanto, o direito à educação.
\end{abstract}

Palavras-Chave: Alfabetização de Jovens e Adultos; Políticas Públicas; Programa TOPA.

\begin{abstract}
Literacy is a gateway to the process of self-determination, empowerment, insertion and social reintegration. It is believed that literacy provides access to better working conditions and income, as well as promoting important changes in the relationship of young people, adults and the elderly as the world. In view of this reality, the present article aims to analyze the All for Literacy Program - TOPA as a factor of social ascension in the Municipality of Candeias - Bahia.For the development of this study, the exploratory descriptive method was adopted, with a qualitative approach and a questionnaire to collect data on the subject in question. The referred work was developed based on bibliographic research with the purpose of building a theoretical foundation from knowledge already cataloged as: books, scientific articles, magazines, reports, periodicals, internet among other sources. Thus, in this article, the Todos for Literacy Program - TOPA was analyzed as a factor of social ascension in the municipality of Candeias. In view of the data obtained, it was concluded that the program has precariously contributed to the social rise of those who participate in it, because, in view of its weaknesses, the continuity of studies is not guaranteed, thus denying the right to education.
\end{abstract}

Key words: Youth and Adult Literacy; Public policy; TOPA program.

\section{Introdução}

Com o advento da Lei de Diretrizes e Bases da Educação Nacional, LDB 9394/96, a Educação de Jovens e Adultos começa a integrar o nível da Educação

\footnotetext{
${ }^{1}$ Mestre em Ciências da Educação pela Faculdade Interamericana de Ciências Sociais - FICS. Especialista em Educação Afro Brasileira e Africana pela Visconde de Cairu, Especialista em Estudos Interdisciplinares da Educação Básica, pela UFBA, Especialista em Educação Inclusiva pela FACCEBA. Graduada em Pedagogia pela Unijorge,. Docente e vice gestora da Rede Municipal de Educação de Salvador-BA. Email: ana.caribe@yahoo.com.br

2 Mestre em Ciências da Educação pela Faculdade Interamericana de Ciências Sociais - FICS. Especialista em Educação de Jovens e Adultos - Faculdade Visconde de Cairu (FAVIC). Especialista em Gestão, Coordenação e Orientação Educacional- Faculdade Visconde de Cairu (FAVIC). Pedagoga - Universidade do Estado da Bahia (UNEB). e-mail: rosysaturno32@hotmail.com
} 
Básica, sob a responsabilidade dos municípios. Contudo por falta de concretização de projeto eficaz para essa modalidade de ensino, os avanços e melhorias propostas pela lei não obtiveram êxito nem visibilidade pela sociedade.

O funcionamento das turmas da Educação de Jovens e Adultos (EJA), entretanto, ocorre em locais improvisados ou inadequados, denunciando a não prioridade dessa modalidade de ensino, demonstrando que esta, sempre fora relegada em segundo plano, o que contraria ao proposto pelas legislações e não constituiu uma ruptura com a diretriz predominante na EJA ao longo da história.

O direito à educação é reconhecido nos principais documentos internacionais, como a Declaração Universal dos Diretos Humanos, o Pacto Internacional dos Direitos Econômicos, Sociais e Culturais, a Convenção sobre os Direitos da Criança, a Convenção Americana de Direitos Humanos e o Protocolo de São Salvador. Na Legislação Brasileira a garantia do direito social à educação, esta enumerada no art. 208 da CF/88; no ECA (art. 54) e na LDB/96 (art. $4^{\circ}$ ) como deveres do Estado.

$\mathrm{Na} \mathrm{CF} / 88$, a educação unir-se-á ao rol dos direitos sociais que estão relacionados no Título dos Direitos e Garantias Fundamentais. A mesma constituição enuncia a educação como direito de todos, dever do Estado e da família. $\mathrm{O}$ art. 208, parágrafos $1^{\circ}$ e $2^{\circ}$ da $C F / 88$ dispõe que o acesso ao ensino fundamental obrigatório e gratuito é direito público subjetivo e o não oferecimento do mesmo pelo Poder Público, ou sua oferta irregular, implica responsabilidade da autoridade competente.

Dessa forma, objetivou-se analisar o Programa Todos pela Alfabetização (TOPA), como fator de ascensão social no município de Candeias -BA. Em relação a metodologia utilizou-se pesquisa bibliográfica e documental além de um estudo descritivo exploratório de cunho qualitativo, com utilização de entrevistas e questionário informal como instrumento de coleta de dados.

Os atores da pesquisa foram o gestor municipal do Programa TOPA, coordenadores de turmas, e alguns alfabetizadores que atuaram em mais de duas etapas do Programa e alfabetizandos. Os documentos pesquisados referem-se à Proposta Pedagógica do Programa Todos pela Alfabetização e os documentos oficiais que tratam do Programa no contexto municipal, entre eles o termo do Convenio e a Resolução do FNDE e os relatórios das ações desenvolvidas no município de Candeias.

\section{A Gestão municipal do TOPA}


No ano de 2007, o município de Candeias faz adesão ao Programa TOPA, pois, a cidade registrava uma alta taxa de analfabetismo entre os jovens, adultos e idosos, demandando, portanto, urgência da oferta de alfabetização para esse público. É conveniente salientar que o elevado índice de analfabetismo no município de Candeias nos anos de 2000 e 2010 supera a média nacional, conforme mostra a Tabela 1.

Tabela 1: Taxa de analfabetismo no município de Candeias 2000 - 2010

\begin{tabular}{|l|l|l|l|l|l|}
\hline Ano & População & Alfabetizada & $\begin{array}{l}\text { \%) } \\
\text { Alfabetizada }\end{array}$ & $\begin{array}{l}\text { Não- } \\
\text { alfabetizada }\end{array}$ & $\begin{array}{l}\text { \%) não- } \\
\text { alfabetizada }\end{array}$ \\
\hline $\mathbf{2 0 0 0}$ & 76.783 & 46.107 & 60.05 & 6.949 & 9.05 \\
\hline $\mathbf{2 0 1 0}$ & 83.158 & 57.017 & 68.56 & 5.312 & 6.38 \\
\hline
\end{tabular}

Fonte: IBGE, 2018.

O índice de analfabetismo no município supera a média nacional, e não obstante, os dados municipais revelam um declínio no número de matrícula na Educação de Jovens e Adultos, conforme descrito na Tabela 2.

Tabela 2: Número de matrícula EJA - Educação de Jovens e Adultos no município de Candeias

\begin{tabular}{|c|c|}
\hline Ano & Número de matrícula \\
\hline 2016 & 2.051 \\
\hline 2017 & 1.910 \\
\hline 2018 & 1.881 \\
\hline 2019 & 1.785 \\
\hline
\end{tabular}

Fonte: Inep, 2019

Diante do exposto, é possível conjecturar que a educação de jovens, adultos e idosos, primordialmente a alfabetização em Candeias configurava-se em um grande desafio a ser superado, pois, os dados nos remetem a considerar que o número de analfabetos no município estava em crescimento. Dos 5.312 jovens, adultos e idosos analfabetos do município, apenas 1.785 encontrava-se matriculados nas classes de EJA, o que representava apenas um terço do total. Vale ressaltar que os alfabetizandos matriculados nas turmas de alfabetização do Programa TOPA não foram contabilizados.

O TOPA, em suas diferentes etapas, sob a responsabilidade da Secretaria Estadual de Educação através das Diretorias Regionais de Educação - DIREC's, vem desde 2007 mobilizando a sociedade, selecionando e formando alfabetizadores e coordenadores de turmas, com o objetivo de promover a inserção e a reinserção dos jovens, adultos e idosos maiores de 15 anos na educação básica visando possibilitar 
a estes, a elevação da sua escolaridade, bem como o exercício pleno da cidadania, oportunizando assim, uma formação cidadã.

Ao aderir ao programa e matricular alunos em turmas de alfabetização, o município conta com apoio técnico para implementar as ações propostas pelo programa, no que tange a garantia da continuidade dos estudos aos alfabetizandos por meio de resoluções específicas publicadas no Diário Oficial da União e do Estado. É papel do município e da entidade que adere ao TOPA, nomear um gestor local para o Programa. Cabe ao gestor acompanhar, monitorar e desenvolver as ações do TOPA no município, assim como, alimentar o sistema, registrando os voluntários bolsistas e além de cadastrá-los juntamente com os alfabetizandos e suas respectivas turmas.

Para serem selecionados como alfabetizadores e/ou coordenadores de turma do PBA/TOPA, os candidatos devem ser prioritariamente professores da rede pública de ensino. Convêm evidenciar que tal priorização advêm da orientação do próprio programa, entretanto, não se configura em impedimento para o ingresso de pessoas com formação em nível médio completo candidatar-se para a função de alfabetizador.

Em Candeias, apenas alguns alfabetizadores e coordenadores do TOPA, tinham vínculo empregatício com o município, entretanto, a maioria desses voluntários bolsistas inscritos eram pessoas sem experiencia em ensino, há registros orais que em etapas iniciais, houve a participação de bolsistas sem a formação exigida, sendo a carência de pessoas com a formação adequada em determinadas comunidades, a justificativa para o ingresso dos mesmos.

Na estrutura de funcionamento do Programa, todos os alfabetizadores devem atuar nas comunidades que residem, porque as despesas de transporte para alfabetizadores de outras localidades não é financiada pelo Programa. Desse modo, pode-se pressupor o motivo pelo qual o perfil do profissional selecionado para atuar nas turmas de alfabetização do TOPA, não obedece ao que é previsto pelo programa. A precarização do ensino para jovens, adultos e idosos é perceptível nas orientações contraditórias geradas pela falta de priorização da alfabetização deles. A respeito disso, o gestor local do TOPA afirma que

[...] é feito uma chamada pública no intuito selecionar professores formados, principalmente os da rede municipal para assumir as turmas do TOPA, mas a maioria deles não têm interesse. A alegação é sempre a mesma: o Programa paga muito pouco, se comparado ao salário que eles recebem na rede, além disso, o gestor municipal afirma não ter condições de complementar a bolsa dada aos voluntários. Assim sendo, a maioria dos profissionais da rede preferem buscar um emprego que paguem um valor que eles desejam (GESTOR LOCAL DO TOPA, 2019). 
O que fica evidenciado na fala do gestor local é que não há uma preocupação efetiva com a alfabetização dos jovens, adultos e idosos do município, percebe-se ainda que, embora tenha aderido ao Programa TOPA, o gestor municipal não compreende a importância da alfabetização para aqueles que buscam retomar seus estudos. Não se pode perder de vista que a existência do programa não desobriga o gestor municipal de ofertar classes de alfabetização para seus munícipes.

Contudo, não se pode esquecer que historicamente a EJA sempre foi renegada, ocupando lugar anódina na sociedade, principalmente quando se refere ao seu financiamento. Embora a educação de jovens, adultos e idosos tenha sido inclusa como modalidade de ensino da educação básica, O FUNDEB não foi capaz de solucionar as questões relativas ao analfabetismo, evidenciando, portanto, o lugar da EJA nas políticas públicas, reafirmando assim que:

O Fundeb é uma exigência, embora o pensamento dos legisladores e de autoridades dirigentes só entenda sua existência condicionada a custos mais baixos para a EJA, revelando o lugar que a modalidade ocupa não apenas nas políticas públicas, mas também no imaginário social: educação pobre para gente pobre (FÓRUNS DE EJA BRASIL, 2005, p. 4).

É inegável que houve avanço no que diz respeito ao financiamento da EJA, em virtude das transformações ocorridas na base constitucional do FUNDEB, embora isso não tenha sido suficiente para elevar a EJA ao lugar de educação prioritária, quando trata-se da aplicação de recursos financeiros em seu favor.

Em relação a formação mínima para atuar como coordenador de turma, o programa exige que os profissionais tenham nível superior ou estejam cursando. Assim sendo, ainda que os candidatos a coordenadores de turmas não tenham vínculo empregatício com a Rede Municipal de Ensino, normalmente são ligados à área educacional de modo formal ou informal. Torna-se necessário destacar que mesmo assim, não há garantia que todos atuam ou já atuaram efetivamente.

No entanto, em Candeias durante diversas etapas do programa, a gestão municipal colocava como exigência ímpar para ser coordenador, conseguir um grupo de possíveis alfabetizadores, que por sua vez formariam suas turmas com o número mínimo de alfabetizandos, tudo ocorria mesmo antes da Secretaria Estadual da Educação realizar seleção pública para coordenadores. Em vista disso, o nível de escolaridade não tinha muito valor, possibilitando assim, que pessoas com apenas ensino médio e/ou bacharéis atuassem no programa na função de coordenador.

Dessa forma, fica evidente que o processo de alfabetização executado no município, não atende as Resoluções orientadora do Programa TOPA e por 
conseguinte segue prejudicando aqueles que por muitos anos foram marginalizados, como é o caso dos alfabetizandos, pois, é inconcebível pensar que independentemente da área de formação, todo e qualquer profissional pode alfabetizar, pois:

Caberia aqui perguntar qual é a concepção de coordenação assumida pelo TOPA e, mais que isso, a concepção de alfabetização e o que de fato se espera com isso e qual sociedade é esperada com essa prática. Que tipo de orientação pedagógica pode oferecer aos alfabetizadores, alguém que tenha apenas o ensino médio? Da mesma forma, pergunta-se o que um bacharel em Ciências Contábeis sabe de educação ou alfabetização de jovens e adultos? Legitimar que qualquer pessoa pode ser alfabetizador ou coordenador de turma, sem a devida formação é legitimar que a formação não seja necessária (SILVA, 2016, p.97).

É perceptível que alfabetizar é um ato complexo que exige uma formação específica dos envolvidos nessa tarefa, e promover uma política pública educacional visando erradicar o analfabetismo, perpassa por aspectos pedagógicos, sociais e políticos e toda a sua complexidade. Entretanto, pode-se asseverar que o aspecto pedagógico é considerado irrelevante, haja vista a crença na ideia de que ser alfabetizador é possível a qualquer pessoa, assim, como coordenar turmas de alfabetização de adultos é algo que independe da formação acadêmica.

Contudo, é primordial enfatizar que nas etapas dos anos de 2017 e 2018, este cenário mudou com a realização de processo seletivo para coordenador promovido pela SEDUC a pedido do gestor local. Para tanto, fora realizado chamada pública contendo duas fases: no primeiro momento ocorreu a prova de título para garantir a formação mínima exigida e uma prova escrita que consistia em elaborar um planejamento para uma turma de alfabetização; na fase seguinte, a dificuldade dos coordenadores orientarem os alfabetizadores acerca das práticas pedagógicas apropriadas para alfabetização e pautada nos princípios do programa, foi outro problema detectado em etapas anteriores.

O TOPA tem como objetivo promover uma educação de qualidade para a população de jovens, adultos e idosos, visando afiançar o seu ingresso e permanência na escola e para tanto, torna-se necessário avalizar as oportunidades imprescindíveis à apropriação da leitura e da escrita, criando as condições objetivas para a inclusão social, política, econômica e cultural desses sujeitos (SEC/BAHIA, 2012). E não há como proporcionar a inclusão desses sujeitos oferecendo-lhes uma educação desempenhada por profissionais sem formação apropriada.

Nesse contexto, compreender a educação enquanto chave para o desenvolvimento da sociedade, que deve ser tratada com seriedade e compromisso, 
é condição sine qua non para erradicar o analfabetismo. Para tanto, é imperioso investir e priorizar a formação dos envolvidos na promoção da alfabetização. Entendendo a educação como direito social, econômico e cultural, deve proporcionar o pleno desenvolvimento pessoal, potencializar a autonomia e promover o desenvolvimento pleno da cidadania.

Assim, faz-se mister destacar que a superação dos desafios da gestão do Programa TOPA no município, perpassa pela ampliação e valorização da EJA, bem como, pela administração transparente, eficiente e eficaz dos recursos financeiros, aliado a uma liderança comprometida capaz de sobreviver às crises políticas recorrentes e a corrupção, pois, é sabido que a ingerência dos recursos inviabiliza o desenvolvimento do processo de alfabetização e/ou promove um ensino carente, deficitário tanto em âmbito material quanto humano.

\section{Cadastramento dos alfabetizandos}

A garantia do direito de todos à educação, por conseguinte, à alfabetização é dever do Estado. Em vista disso, o Estado da Bahia, por meio da Secretaria da Educação realiza e amplia parcerias com municípios, instituições de ensino superior, entidades não-governamentais e outras organizações sociais, no intuito de construir políticas públicas voltadas para a educação de jovens e adultos, especialmente no que concerne ao processo de alfabetização.

Almeja-se que um Programa como o TOPA, de tamanha magnitude com objetivos e metas estabelecidas, tenha suas ações desenvolvidas com qualidade visando atingir seus objetivos. Ficou evidente que o processo seletivo dos bolsistas voluntários (coordenador e alfabetizador), por muitas etapas não seguiram as orientações do Programa, o que consequentemente compromete 0 seu funcionamento. Embora isso tenha se modificado nas etapas finais do TOPA no município de Candeias, conforme explicitou o gestor local.

No município de Candeias, o cadastramento do público alvo do Programa TOPA - os alfabetizandos, é feito exclusivamente pelos possíveis alfabetizadores de turmas, que primando pelo direito de participar do programa, saem em suas comunidades em busca do seu público. Vale ressaltar que formar a turma ocorre quase como uma regra, uma imposição, uma condição para ser alfabetizador. Contudo, por se tratar de uma política pública de alfabetização, imagina-se que haverá uma mobilização na cidade para detectar a clientela e possibilitar o acesso de todos interessados. Diante da falta de campanhas de chamamento do público e da condição 
imposta para ser alfabetizador, inicia-se uma corrida em busca de alunos e com ela, a maioria dos vícios do Programa, dentre eles, destacamos a inclusão de familiares e amigos nas turmas, pois, sem isso, seria impossível formar classes de alfabetização, como relatam alguns alfabetizadores.

Percebe-se que o cadastramento dos alfabetizandos é realizado pelas prováveis alfabetizadoras com o único propósito, o econômico, visto que para a maioria deles, a bolsa auxílio paga representa a única fonte de renda. Nesse aspecto, pode afirmar que a proposta social inicialmente pensada pelo Programa ganha contornos particulares, no qual o que prevalece é o interesse privado e meramente financeiro, em detrimento da causa precípua - a alfabetização dos jovens, adultos e idosos da comunidade a qual faz parte, o que contraria o discurso oficial do Secretário da Educação do Estado, que ao falar do Programa asseverou que:

Ao construirmos o TOPA, alguns elementos foram decisivos: o diálogo, a participação, a mobilização social, a intersetorialidade, o investimento em gestão, informatização e formação, a parceria com as universidades e a convicção de que não alcançaríamos os objetivos a que nos propusemos sem a ação conjunta do governo com a sociedade civil (BARRETO, 2014 apud ALVES; GADOTTI, 2014, p. 18).

Verifica-se que sem a mobilização social, o programa fica fragilizado e a mercê dos interesses particulares daqueles que o gere, entretanto, é notório que as ações poderiam ser qualificadas e efetivas, se houver a garantia do cumprimento das orientações dadas pelo Programa e o monitoramento social e efetivo por parte da gestão. O município poderia realizar o cadastramento dos alfabetizados de maneira mais ampla e com logística apropriada, fazendo desse momento uma ação institucionalizada.

É preciso que a cidade assuma sua responsabilidade perante ao programa, repassá-la aos que por motivos diversos almejam fazer parte do TOPA, como alfabetizador é inaceitável, assim como, representa o descaso com aqueles que veem o programa como porta de entrada para a melhoria da sua condição de vida, como é o caso dos alfabetizandos. É inconcebível pensar que um alfabetizador/alfabetizadora, se faz a partir da sua habilidade para formar turmas com determinado número de alunos.

Nesse sentido, surge um questionamento sobre o que fazer para que as orientações do Programa sejam efetivadas, porque a sua implantação e a proposição de aspectos legais não dão conta de garantir o acesso dos analfabetos a essas políticas. Falta entendimento acerca da importância dos parâmetros estabelecidos ao 
se projetar um programa, o que se propõe é idealizado objetivando sanar ou amenizar os problemas. Entretanto, é irrefutável que a lei por si só não garante o pleno acesso ao direito à educação. Torna-se imprescindível que haja uma articulação entre as dimensões política, pedagógica e a administrativa, entendendo que:

São também necessárias ações concretas, materializadas por meio de planos, programas e políticas públicas que deem resposta ao que fixa a lei. Esses, por sua vez, dependem da força política, das diretrizes educacionais e da previsão orçamentária e, cada vez mais, de articulações intersetoriais, intersecretariais e interministeriais - na verdade, em todos os níveis da administração pública, além da parceria entre Estado e sociedade civil [...] (ALVES e GADOTTI, 2014, p.78).

O desenvolvimento das ações e a sua execução depende da gestão do programa, contudo, é preciso ter clareza de que os resultados positivos ou negativos estão intrinsecamente ligados a qualidade da implementação dessas ações e implicam diretamente no alcance dos objetivos propostos. Nesse cenário, presumese uma mudança de postura perante o Plano Nacional de Educação - PNE sancionado pelo Governo Federal, que estabeleceu:

A erradicação do analfabetismo como sua primeira diretriz, incluindo a meta no 9 no propósito de elevar para 95\% a taxa de alfabetização da população de 15 anos, sendo que esse prazo seria até 2015 e erradicar até 2020 o analfabetismo absoluto, assim como, reduzir na metade a taxa de analfabetismo funcional (Ibid. p. 77).

É importante salientar que o Programa TOPA surge com a premissa de ser diferentes dos seus antecessores, no tocante a erradicação do analfabetismo. Entretanto, na realidade do município de Candeias, essas diferenças ocorreram gradativamente e não foram tão significativas conforme idealizado, mas é inegável que atingir seus objetivos e metas, seja o desejo de todo e qualquer programa institucionalizado e o TOPA avança ao possibilitar novas formas de parceria entre as organizações, assim, é:

Difícil dizer que haja elementos novos no Programa TOPA, mas é difícil também afirmar ele não traz nenhuma novidade. Sem dúvida o TOPA representa a continuidade de uma história no contexto da alfabetização de pessoas jovens e adultas. De todos os modos, o TOPA se afirma como uma política pública que se organiza para atender a alfabetização de pessoas jovens e adultas. Alfabetizar, na perspectiva do Programa TOPA é, além de saber ler e escrever, exercitar a cidadania plena, ser educado para o trabalho e conviver com a diversidade social, entre outras (SILVA, 2016, p.100-101).

Desse modo, pode-se conjecturar que o Programa TOPA, contribuiu com a história da alfabetização e buscou inovar para destacar-se dos demais programas de alfabetização anteriores a eles. Contudo, a lei por si só não resolve os problemas do analfabetismo em Candeias, na Bahia. É preciso unir forças visando amenizar o 
analfabetismo e erradicar suas causas. As transformações foram propostas, no entanto, é preciso também investir nas mudanças de posturas e mentalidades dos envolvidos no TOPA.

\section{Fragilidade no Processo de Migração Para a Rede Regular de Ensino}

Oferecer o aprendizado e ampliando o domínio da leitura e escrita, das operações lógico matemáticas, bem como, a aplicação destes conhecimentos no cotidiano dos jovens, adultos e idosos que não tiveram acesso à escolarização regular é a concepção de Alfabetização do Programa TOPA. Entretanto, o tempo de cada etapa (dura entre seis (6) ou oito (8) meses), é insuficiente para que todos os alfabetizandos sejam efetivamente alfabetizados e a continuidade dos estudos tem a configurar-se uma utopia.

A continuidade aos estudos, por meio da migração coletiva dos alfabetizandos do TOPA para a rede regular de ensino, no município de Candeias nunca ocorreu, nenhuma política efetiva de migração foi implementada. Apesar da maioria das turmas funcionarem em escolas públicas municipais e as aulas serem realizadas no turno intermediário (das $17 \mathrm{~h}$ às $19 \mathrm{~h} 30 \mathrm{~m}$ ) e noturno, horário em que também acontece as aulas regulares da EJA.

O gestor informou que houve até vontade por parte da equipe do Programa, mas que a proposta ficou a cargo unicamente do gestor local, que no intuito de ver a migração dar certo, realizou diversas reuniões com gestores escolares, secretário municipal de educação, coordenadores, alfabetizadores e alfabetizandos do TOPA, conscientizando a todos acerca da importância de garantir não apenas o acesso mas também a continuidade dos alfabetizandos.

Visitas às turmas de alfabetização do programa para incentivar os alfabetizandos a dar continuidade aos seus estudos, bem como, propor aos gestores escolares uma parceria que resultaria em fortalecimento da EJA em suas Unidades Escolares e consequentemente no município, que há muitos anos vem sofrendo com a evasão. Infelizmente, o acordo firmado entre o Programa e o município no ato da assinatura do convênio, no que tange à garantia da continuidade dos estudos dos alfabetizandos, não era cumprido pelos gestores municipais.

Outro fator que fragiliza a migração dos alfabetizandos para o ensino regular é a localização das turmas dos distritos (zona rural), que em sua maioria funcionam em locais de difícil acesso, nos quais não há escolas e quando há escola, não funciona no noturno; não tem professor efetivo e o número de alfabetizandos não justifica a 
contração desse profissional, impossibilitando assim, a continuidade dos estudos para os alunos.

Para tanto, seria necessário que a secretaria de educação disponibilizasse um veículo para fazer o transporte desses alfabetizandos, mas não se pode perder de vista o perfil desses alunos. Eles são jovens, adultos e idosos que trabalham ou tem uma vida com atribuições diversas e que chegam às turmas cansados e muitas vezes atrasados. Como garantir a continuidade, permanência e assiduidade desse, visto teriam que adequar sua rotina aos horários do transporte, como relatou uma alfabetizadora A (2019):

\begin{abstract}
Meus alunos não têm como ir para a escola, porque não tem escola na comunidade e a escola que atende a modalidade EJA é muito distante. Seria necessário ter o ônibus, mesmo assim, eles não aguentariam, pois, trabalham durante o dia. $\mathrm{O}$ ideal é permitir que eles estudem na comunidade. $\mathrm{Na}$ incerteza, da garantia desse direito, os alunos preferem permanecer no TOPA.
\end{abstract}

Isso para não falar dos problemas existentes na dinâmica do transporte escolar municipal, que alguns deles conhecem de perto, porque seus familiares, amigos e vizinhos sofrem diariamente com essa realidade. Entretanto, faz-se mister explicitar que o município tem um número suficiente de unidades escolares que atendem a modalidade da EJA, dos seis (6) distritos existentes, apenas um (1) não conta com o atendimento a clientela de Educação de jovens, adultos e idosos, embora possua escola. Convêm alertar que Candeias ainda conta com comunidades longínquas que não tem escolas, o transporte em alguns casos não chega e os alfabetizandos dessas localidades não tem como estudar em outro local que não seja na sua comunidade.

Apesar da logística, dificultar o atendimento de/em alguns distritos, há alfabetizandos do TOPA que aceitavam o desafio e matriculam-se na rede regular de ensino. Estes são encaminhados pelos coordenadores ou alfabetizadores de turmas e raros casos, são os que eles mesmos que procuram a instituição de ensino e efetivam suas matrículas.

A outra parcela de alunos do TOPA se negam a prosseguir os estudos e apontam diversos motivos para justificar sua postura. Dentre os motivos alegam que não tem como comprar seu material de estudos, a distância entre sua residência e a escola, a falta de vínculo com os professores, que segundo a concepção deles, isso impactaria na forma como se daria seu aprendizado, pois, que não terão a devida atenção, dentre outras coisas. 
Como o alfabetizador faz parte da comunidade, seu vínculo com os alfabetizandos é mais próximo porque grande parte deles tem laços de amizades ou familiar, e isso proporciona uma segurança aos alunos na hora de solicitar apoio no decurso do aprendizado. Alguns alfabetizadores defendem a ideia de continuidade do Programa TOPA, sugerindo que ele deveria abarcar toda a EJA I, ou seja, o ensino fundamental $\mathrm{I}$.

Nessa perspectiva, pode-se afirmar que tanto alfabetizandos quanto alfabetizadores, alimentam a dependência alicerçada no vínculo construído no programa ou em âmbito familiar, o que é prejudicial para o processo educativo, pois, não há como seguir os alfabetizandos/alunos por toda vida. É preciso despertar nos alfabetizando a autonomia, bem como, promover o desenvolvimento pleno da cidadania.

Nesse contexto, cabe aos coordenadores e aos alfabetizadores o papel social de articulador desse processo de transição, entre a saída do programa e a entrada no ensino regular. Muitos são os desafios a serem enfrentados pelos alfabetizandos no que se refere à continuidade dos estudos, conforme as palavras do entrevistado $A$, que reitera:

\begin{abstract}
A educação é de responsabilidade do poder público. Buscamos incansavelmente a continuidade dos estudos dos alfabetizandos, entretanto, trata-se de uma tarefa muito difícil, principalmente se não há apoio, se não há uma preocupação real dos governantes. Entendemos que a implantação de uma escola para adultos em cada localidade é impraticável, mas precisamos pensar estratégias para atender esses alunos oriundos do Programa TOPA, promovendo chamada pública para matriculá-los no ensino regular. Sem isso o programa passa a ser forjado, caindo no descrédito, no qual, os alfabetizadores fingem que alfabetizam e os alfabetizandos fingem que são alfabetizados.
\end{abstract}

O direito dos jovens, adultos e idosos à escolarização é de responsabilidade do município, independentemente da existência ou não de programas de alfabetização. É indispensável salientar que esse direito está garantido pela LDB 9394/96, mas os dispositivos legais não são capazes de assegurar a efetividade dessa conquista, pois:

[...] a realização dessas expectativas e do próprio sentido expresso da lei entra em choque com as adversas condições sociais de funcionamento da sociedade em face dos estatutos de igualdade política por ela reconhecidos. É inegável também a dificuldade de, diante da desigualdade social, instaurar um regime em que a igualdade política aconteça no sentido de diminuir as discriminações. Além disso, muitos governos proclamam sua incapacidade administrativa de expansão da oferta perante a obrigação jurídica expressa (CURY, 2002, p. 247). 
Assim sendo, é cogente a implementação do direito à educação, ao município cabe desenvolver ações com vistas na promoção de uma "[...] educação escolar fundante da cidadania, [...] que visam à participação de todos nos espaços sociais e políticos e, mesmo, para reinserção no mundo profissional” (lbid., p. 246).

De acordo com os entrevistados, muitos alfabetizandos permaneciam no TOPA por mais de uma etapa, usando como justificativa para sua permanência, a vontade de estudar e a impossibilidade de frequentar turmas de EJA, mas outras justificativas são reveladas nos discursos, sendo o paternalismo ávido dos alfabetizadores, uma das causas mais forte nesse processo.

Embora esmerem-se nos discursos em prol da causa social, a realidade revela que diante da responsabilidade do alfabetizador formar sua turma, é conveniente permitir a permanência dos antigos inscritos no programa para atingir a quantidade mínima exigida para formar a turma. Contudo, ao longo das etapas do Programa, algumas mudanças ocorrem no sistema de cadastramento de alfabetizandos, conforme explicitado nas palavras do gestor local:

[...] O sistema bloqueia agora a rematrícula do aluno em etapas consecutivas. Antes podia cadastrar, mas têm alfabetizador que coloca o aluno encostado, sem matrícula. O problema é que está ficando difícil de formar turma, pois, tem muito tempo que tem esses programas. Quem queria estudar já está estudando, então esses programas devem mudar sua filosofia ou se acabarem. Os alfabetizadores fazem de tudo para formar a turma porque o interesse maior é a bolsa. O desemprego é grande (GESTOR LOCAL DO TOPA, 2019).

Frente ao exposto, evidencia-se que o Programa TOPA no município Candeias, tem funcionado em desacordo com as suas orientações. É perceptível que o processo de alfabetização dos jovens, adultos e idosos é o que menos importa. O gestor aponta diversas irregularidades, dentre elas, o cadastramento de diversos membros da família para garantir a bolsa, o não funcionamento de algumas turmas ou ainda, turmas com infrequência ou frequência irregular dos alfabetizandos, porque a maioria deles foram cadastrados e nem sabem.

O gestor local esclarece que apesar de possuir funções meramente burocráticas como preenchimento de fichas, relatórios, encaminhamento de frequência para pagamento das bolsas etc., ele sente-se na obrigação de acompanhar e monitorar todas as ações desenvolvidas nas turmas. Embora sua autonomia para solucionar os problemas existentes no Programa seja mínima.

Outro ponto que merece ressalva é o pagamento da última bolsa auxílio ser condicionada aos números de alunos alfabetizados apresentado no relatório final. 
Diante disso, constata-se que uma alfabetização maciça, pois, é inegável que nenhum alfabetizador que tenha desempenhado seu trabalho queira ser prejudicado financeiramente, sem falar no comprometimento que essa pode causar aos resultados acerca da efetividade do Programa na erradicação do analfabetismo.

Contudo, o condicionamento entre bolsa e aluno alfabetizado não fora encontrada em nenhum documento oficial consultado do Programa. Entretanto, o gestor local confirmou a fala dos alfabetizadores. Partindo dos relatos orais dos bolsistas, em relação a avalição interna realizada pelo próprio Programa, o teste cognitivo de entrada, o qual detecta o nível de aprendizagem dos alfabetizandos, este não cumpre seu papel de instrumento diagnóstico, haja vista que seus resultados não servem de base para a elaboração de uma proposta de intervenção, muito menos como ponto de partido para direcionar o trabalho pedagógico.

São inúmeros desafios enfrentados pela gestão do Programa TOPA, principalmente em relação ao recebimento do material pedagógico, da merenda e dos encaminhamentos dos alunos aos serviços sociais parceiros como oftalmologista, dentre outros. Em relação ao material didático, há uma demora na chegada dele, invalidando a promessa feita aos alfabetizandos no ato do cadastro, de iniciar as aulas de posse do material. A merenda por diversas etapas não foi disponibilizada, quando acontece chegar, vem com muito atraso. Vale ressaltar que os materiais da merenda são pré cozidos e na falta de merendeira, cabe ao alfabetizador preparar esse lanche para sua turma.

Os exames oftalmológicos ocorreram em pouquíssimas etapas, assim sendo, caíram na descrença da maioria dos alfabetizandos e consequentemente no desinteresse do público pelo programa, conforme relata alguns entrevistados:

Meus alfabetizandos afirmam que só frequentará a escola regular se receber material pedagógico e merenda e se a escola for próxima a residência deles. (ALFABETIZADORA E, 2019).

O TOPA é cheio de promessas, mas quase nada é cumprido, é promessa de óculos, de material pedagógico e de merenda, mas não cumpre nenhuma delas. Nós conquistamos os alfabetizandos oferecendo essas coisas e quando não chegam, os alunos abandonam as turmas. Um dos questionamentos dos alunos a respeito da escola de ensino regular é se nele as coisas são iguais no TOPA, porque se for precário, é melhor nem dar continuidade nos estudos (ALFABETIZADORA F, 2019).

Apesar das dificuldades, alfabetizandos e alfabetizadores reconhecem a importância do programa na vida deles, o quanto eles aprenderam coisas novas, relembraram outras esquecidas, aprenderam ler e escrever, trocaram experiências, 
vislumbraram novos horizontes tanto na vida pessoal quanto na vida profissional. Nesse aspecto pode-se afirmar que:

\begin{abstract}
Quem procura curso de alfabetização de adultos quer aprender a escrever e a ler sentenças, frases, palavras, quer dizer alfabetizar-se. A leitura e a escrita das palavras, contudo, passa pela leitura do mundo. Ler o mundo é um ato anterior à leitura da palavra. O ensino da leitura e da escrita das palavras a que falte o exercício crítico da leitura e da releitura do mundo é, científica, política e pedagogicamente capenga (FREIRE, 1992, p. 79).
\end{abstract}

Contudo, é inegável que o aprendizado de leitura e escrita é um processo complexo, portanto, o período proposto pelo TOPA é insuficiente para alcançar tal propósito. Alguns alfabetizadores relatam que suas vidas também mudaram, pois, a aproximação com os mais velhos possibilitou mudança de comportamento, abertura de novas perspectivas e os motivaram a dar continuidade aos estudos, porque eles identificaram-se com a atividade desempenhada.

Frente as ações desenvolvidas e mediante os relatos dos entrevistados, fica evidente que as questões pedagógicas não é a prioridade, a precarização impede que o gestor local e coordenadores acompanhem e monitore as turmas efetivamente. Segue relato: De fato, eu acompanho o desenvolvimento das atividades pedagógicas do TOPA, mas com muita dificuldade, pois, não há carro disponível para isso. Embora essa seja uma atribuição do coordenador de turma, pois, segundo as orientações do Programa, o coordenador deve visitar as turmas e auxiliar os alfabetizadores em suas atividades didático-pedagógicas (GESTOR LOCAL DO TOPA, 2019).

Constata-se dessa forma, que o município não tem honrado com os compromissos firmados oficialmente, demonstrando, portanto, uma falta de compromisso com a educação de jovens, adultos e idosos, reafirmando assim, o descaso que por muito tempo a modalidade de ensino vem sofrendo. Nesse sentido, pode-se conjecturar que o TOPA não tem cumprido seu papel de política pública. Verifica-se no posicionamento do gestor local do programa, que os entraves que impedem a execução do TOPA, são meramente administrativos e burocráticos. $O$ declínio no número matrícula na EJA comprovam que a migração dos alfabetizandos do TOPA para rede regular de ensino é mínima ou quase inexistente.

\title{
O contexto da formação dos alfabetizadores
}

A formação dos alfabetizadores é uma das ações fundamentais do conjunto de ações necessárias para a implementação do Programa TOPA. Entende-se por formação, os processos em que a teoria e a prática se transformam por meio da 
reflexão crítica, na qual, os sujeitos buscam a construção da sua própria autonomia intelectual. Quanto à formação continuada, pode-se afirmar essa busca só será eficaz e significativa se o sujeito se entender como inacabado, em constante transformação.

Entendida como processo permanente e constante de aperfeiçoamento dos saberes necessários à atividade dos educadores, a formação continuada de professores é realizada após a formação inicial e tem como objetivo assegurar um ensino de qualidade para aos alunos. Mas como garantir essa qualidade de ensino quando a formação inicial e continuada dos alfabetizadores ocorrem no meio ou final de cada etapa do programa e a maioria dos alfabetizadores não possuem formação específica para alfabetizar, como é o caso do município de Candeias? A respeito disso:

A falta de oportunidades de profissionalização e de formação para educadores tem um impacto negativo sobre a qualidade da oferta de aprendizagem e educação de adultos, assim como o empobrecimento do ambiente de aprendizagem, no que diz respeito a equipamentos, materiais e currículos (UNESCO, 2010, p.21).

Que sentido haverá numa formação que acontece do meio pro final do Programa, quando na verdade essa ação deveria ser a principal, assim, questiona-se o gestor local (2019) ao desabafar que "a formação precisa acontecer antes de começar as aulas, como o próprio nome diz: formação Inicial, portanto, deve ocorrer no início e não no meio ou no fim. A formação do jeito que acontece não tem sentido".

Nesse contexto, a formação acaba não contribuindo para a prática, ou seja, não atende as necessidades do alfabetizador, haja vista o período em que ela acontece ser muito curta, e as abordagens serem excessivamente pautada em teorias complexas para quem não tem nenhuma relação com a educação. Entretanto, após a formação, "os alfabetizadores reconhecem suas lacunas, deficiências e necessidades formativas com mais propriedade" (MIRANDA; SILVA, 2016, p.19).

A Formação continuada deve proporcionar aos alfabetizadores vivências que possibilitem a sua participação ativa no mundo no qual está inserido, e a incorporação dessas vivências ao conjunto de saberes do seu fazer docente, permitindo assim, uma reflexão constante da sua prática pedagógica. A formação dos alfabetizadores e coordenadores de turma do TOPA, no município de Candeias é oferecida pela Universidade do Estado da Bahia (UNEB). A unidade formadora, UNEB, realiza a formação em dois níveis e momentos, sendo no início de cada etapa e ao longo dela.

O primeiro momento, denominado formação inicial, oferece o curso com quarenta horas de duração, e no segundo, a formação continuada são mais vinte 
horas. A formação inicial e continuada objetiva fazer com que os alfabetizadores considerem e se apropriem da cultura dos alfabetizandos e:

Esses níveis e momentos dialogam entre si, constituindo a totalidade da formação esperada para educadoras e educadores do Programa, trabalhando o processo de alfabetização na dimensão e complexidade envolvidas (ALVES; GADOTTI, 2014, p. 141)..

É preciso que a formação contribua com a retomada do processo de escolarização dos alfabetizandos, possibilitando que eles se sintam seguros, autônomos e confiantes. Faz-se necessário compreender as práticas de formação continuada como instrumento capaz de englobar a diversidade em âmbito escolar e na vida cotidiana, como descrito nos referenciais do CNE:

\begin{abstract}
A educação, como chave indispensável para o exercício da cidadania contemporânea, vai se impondo cada vez mais nesses tempos de grandes mudanças e inovações nos processos produtivos. Ela possibilita ao indivíduo jovem e adulto, retomar seu potencial, desenvolver suas habilidades, confirmar competências adquiridas na educação extraescolar e na própria vida, possibilitar um nível técnico e profissional mais qualificação (BRASIL, 2000, p. 11).
\end{abstract}

Os alfabetizadores, nos momentos de formação, necessitam conhecer os princípios teórico-metodológicos do Programa TOPA, o pensamento de Paulo Freire e a base das propostas de Emília Ferreiro e Magda Soares. Entretanto, pode-se esclarecer que:

Antes de qualquer tentativa de discussão de técnicas, de materiais, de métodos para uma aula dinâmica, assim, é preciso, indispensável mesmo, que o professor se ache - repousado no saber de que a pedra fundamental é a curiosidade do ser humano (FREIRE, 2007, p. 86).

O planejamento está voltado para o principal sujeito das ações educativas, o alfabetizando e suas especificidades socioculturais são indicadores primordiais nessa construção. As práticas educativas precisam dar conta desse grande desafio social que é o ensino da leitura e da escrita dos jovens, adultos e idosos, levando em consideração o profissionalismo do professor alfabetizador.

Outro problema detectado no programa é a falta de formação dos alfabetizadores. Pessoas, que na maioria das vezes possuem formação em ensino médio, sem nenhuma relação com a educação e que repentinamente tornam-se alfabetizadores de jovens, adultos e idosos em um Programa dessa dimensão, com metas e objetivos que buscam erradicar o analfabetismo. Nessa perspectiva, a formação continuada deve possibilitar a superação de deficiências relacionadas ao fazer docente, em vista disso, aponta alguns caminhos que são: 
O primeiro passo é a contribuição para esse diálogo com os alfabetizadores, que em muitas situações não tinham formação inicial em curso de pedagogia ou magistério, mas tinham o desejo político e social de ajudar a alfabetizar outras pessoas. [...] Por outro lado, existiam algumas carências conceituais, epistemológicas, relacionadas ao fazer docente, e esse se constituiu em um dos grandes desafios, pois, tínhamos pessoas conscientes de seus papéis sociais e que estavam buscando a formação para cumprir bem esse papel, mas chegavam até nós com uma série de lacunas conceituais do fazer pedagógico, e o tempo de formação era muito pequeno para dar conta desse processo (OLIVEIRA, 2014, p. 2).

Neste sentido, a formação continuada carecerá ser desenvolvida para proporcionar a autonomia profissional dos alfabetizadores, pois, constata-se que os alfabetizadores não conseguem transpor a formação para a sua práxis, principalmente os que não tem experiência com educação e são egressos do ensino médio. Eles conseguem construir o conhecimento teórico durante a formação, mas não conseguem relacioná-lo à sua prática. É nessa realidade que o docente torna-se "sujeito e não objeto da formação [...]. Por isso é necessário um modelo de aprendizagem cujas metas sejam dirigir-se a si mesmo e orientar-se para a capacitação da autonomia" (IMBERNÓN, 2011, p.87).

Em decorrência da não compreensão dos aspectos teórico-metodológicos relacionados ao processo de ensino-aprendizagem e ao ato de alfabetizar, a maioria dos alfabetizadores limitam-se apenas ao processo de ensinar ler e escrever o próprio nome, conforme explica o entrevistado E (2019):

Desde o primeiro dia de aula meus alunos já me pedem para ensinar a escrever o nome [...]. A gente tenta trabalhar os textos e as demais coisas sugeridas na formação, mas tem muitos alfabetizandos que não gostam. [...], então eu vou fazendo as duas coisas, mas preocupo mais em ensinar a ler e escrever o nome.

Percebe-se, portanto, que há uma fragmentação entre o proposto e o realizado, o que compromete $o$ ato de alfabetizar, assim como, constata-se que a prática e as teorias aprendidas durante o processo formativo não estão relacionadas, portanto, a concepção de alfabetização praticada contraria a concepção de alfabetização do Programa, nesse aspecto, para que haja essa articulação entre teoria e prática assevera-se que:

Ainda é necessário que os programas de alfabetização de jovens, adultos e idosos, como é o caso do TOPA, promovam um processo de formação de educadoras e educadores que esclareça, por meio de estudos, reflexões e debates, quem são essas educandas e educandos que frequentam as aulas de alfabetização. Portanto, há dois desafios a serem enfrentados: um de natureza teórica e outro de natureza teórico-metodológica, quais sejam: 1) Conhecer, de maneira geral, quem é o jovem, o adulto e o idoso, nas suas especificidades; 2) Conhecer as especificidades desse jovem, adulto e idoso do estado da Bahia e que frequentam as aulas do TOPA (ALVES; GADOTTI, 2014, p. 145). 
Assim, torna-se imprescindível que a formação seja repensada considerando os sujeitos da formação, os saberes que serão formados e como esse saber será transposto para a práxis.

\section{Considerações}

Muitos são os entraves relacionados aos aspectos políticos-pedagógicos vinculados à alfabetização de jovens, adultos e idosos. Contudo, os desafios relacionados à gestão político-administrativa são ainda maiores, pois, a eficácia dessa gestão depende da força política, das diretrizes educacionais, da previsão orçamentária e das articulações intersetoriais, intersecretariais e interministeriais, além da parceria entre Estado e sociedade civil. Nessa direção, é indispensável o alinhamento e a articulação entre as dimensões política, pedagógica e administrativa.

Contudo, a realidade municipal do Programa nos remete a pensar que o alinhamento e a articulação, têm sido insuficientes para dar conta das situações essenciais que dão suporte ao desenvolvimento do TOPA. Afinal, se há articulação entre as dimensões, é inexplicável e inconcebível que o programa seja autorizado a iniciar suas aulas sem que as questões pedagógicas e administrativas/financeiras estejam engendradas.

Convêm enfatizar que cabe ao Estado a competência e a autonomia para determinar todas as ações e a periodicidade que serão realizadas em cada etapa. Ao município cabe localizar, identificar, mobilizar e cadastrar jovens, adultos e idosos não alfabetizados para ingressar nas turmas de alfabetização, bem como garantir que os voluntários participem efetivamente das formações.

Nesse contexto, não se pode avaliar o Programa TOPA tomando por base as dificuldades, falhas ou rigor metodológico, é preciso levar em consideração as mudanças sociais, econômicas e culturais causada na vida do alfabetizando. A educação de adultos precisa primar pela melhoria das condições de vida do aluno. Desse modo, a alfabetização de jovens, adultos e idosos precisa ser concebida como um processo capaz de promover mudanças na vida do alfabetizandos, um processo de autodeterminação, empoderamento e inserção e reinserção social.

\section{Referências}

ALVES, A. J; GADOTTI, M. (Orgs). TOPA: Todos Pela Alfabetização: Bahia 20072014 - São Paulo: Instituto Paulo Freire, 2014. 
BAHIA. Secretaria da Educação do Estado da Bahia. Relatório do Programa Brasil Alfabetizado do Estado da Bahia - Programa Todos pela Alfabetização etapas 2007 a 2010. Bahia: SEC/TOPA, 2012.

BAHIA. Programa Todos pela Alfabetização - TOPA. Disponível em: www.sec.ba.gov.br/topa. 2009.

BRASIL. LEI N 9394/96. Diretrizes e Bases da Educação Nacional. Brasília: MEC/SEF, 1996.

BRASIL. Conselho Nacional de Educação. Câmara de Educação Básica. Carlos Roberto Jamil Cury (relator). Parecer CEB11/2000 - Diretrizes curriculares nacionais para a educação de jovens e adultos. Brasília: MEC, 2000.

BRASIL.Programa Brasil Alfabetizado. Disponível in: http://portal.mec.gov.br.2013. Acesso em 05/07/2019

CURY, C.R.J. Direito à educação: Direito à igualdade, direito à diferença. MG: Cadernos de Pesquisa, n. 116, julho/ 2002.

FÓRUNS DE EJA BRASIL. Relatório-síntese do VII Eneja. Luziânia/GO, 31 agosto a 3 setembro 2005. Disponível em: http://forumeja.org.br/node/2026. Acesso em: 15 dez. 2019.

FREIRE, P. Pedagogia da esperança: um reencontro com a pedagogia do oprimido. Notas: Ana Maria Araújo Freire. Rio de Janeiro: Paz e Terra, 1992.

FREIRE, P. Educação e mudança. 30. ed. Rio de Janeiro: Paz e Terra, 2007.

IMBERNÓN, F. Formação Docente e Profissional: formar-se para a mudança e a incerteza. São Paulo: Cortez, 2011.

MIRANDA, H. P; SILVA, F. O. A formação do professor alfabetizador do TOPA na EJA: da teoria à prática. Salvador: UNEB, 2016.

OLIVEIRA, R. Depoimento sobre o Programa Todos pela Alfabetização - TOPA. [2014]. Entrevistador: Alcir de Souza Caria. Salvador, SEC/BA, 2014.

SILVA, O. C. B. A. Alfabetização de pessoas jovens e adultas: um estudo do Programa TOPA no Município de Vitoria da Conquista - BA. Bahia: UESB 2016.

UNESCO. Sexta Conferência Internacional de Educação de Adultos (CONFINTEA VI): Brasília: Marco de Ação de Belém: Declaração de Evidência, 2010. 